\title{
Probable interacción entre Olmesartán y Rosuvastatina por inhibición de OATP1B1
}

\author{
Ma Jesús Rodríguez Arcas \\ Farmacéutica comunitaria de Cartagena. Vocal de SEFAC Región de Murcia.
}

\section{PALABRAS CLAVE}

Interacciones farmacológicas, OATP1B1, Olmesartán, Rosuvastatina

\section{KEYWORDS}

Drug interactions, Olmesartan, Rosuvastatin, OATP1B1

\section{Presentación}

Un varón de 72 años, paciente habitual, acude a retirar su medicación de la farmacia y nos informa de que hace unos meses se le diagnosticó rotura del tendón de Aquiles y tras 20 sesiones de fisioterapia no ha mejorado. Se le ofrece el servicio de Seguimiento Farmacoterapéutico que realizamos durante años en la farmacia. Este estudio de la medicación del paciente está basado en las rutas metabólicas y proteínas de transporte utilizados por los fármacos para detectar posibles interacciones entre ellos; y de esta manera poder relacionar estas interacciones detectadas con la causa de los problemas de eficacia o seguridad observados en el paciente.

El paciente acepta el servicio $\mathrm{y}$ tras la firma del consentimiento informado se establece el siguiente estado de situación (tabla 1).

\section{Estudio y evaluación de la terapia}

El paciente tiene controlados todos sus problemas de salud, excepto su molestia en el tendón y también se trata de un paciente cumplidor tras analizar los criterios del Test Morisky Green. Todas las dosis prescritas de sus fármacos se encuentran dentro de los rangos descritos en la bibliografía y no posee insuficiencia renal o/y hepática.

Observando el estado de situación encontramos que Olmesartán no sólo utiliza para su metabolismo el uso de la proteína transportadora OATP1B1; sino que también actúa como un inhibidor de dicha proteína en un 60,4\%. Esto da lugar a que la metabolización del cualquier fármaco que utilice esta misma proteína se va a encontrar ralentizada y por tanto el fármaco activo se va a acumular en sangre. Dentro de los fármacos prescritos para el paciente, Rosuvastatina utiliza esta misma proteína transportadora para su eliminación del organismo. Aunque la dosis prescrita se encuentra dentro de los márgenes recomendados, podría ocurrir que en este paciente la dosis efectiva sérica de estatina estuviera aumentada por la inhibición de OATP1B1y por tanto la probabilidad de aparición de efectos secundarios estaría también incrementada.

Rosuvastatina presenta como efectos secundarios, entre otros, mialgia y ruptura tendinosa. Del mismo modo, la aparición de efectos adversos se corresponde en el tiempo con la prescripción de Olmesartán. Dado que no parece probable la existencia de otras causas médicas que lo justifiquen podemos determinar una posible interacción entre ambos fármacos como la causa de la ruptura del tendón de Aquiles (3).

El paciente presenta niveles de colesterol ligeramente por encima del rango óptimo y riesgo cardiovascular elevado, de este modo el uso de la estatina es necesaria.

En este caso decidimos mantener Rosuvastatina por ser la única estatina que no utiliza para su metabolización las enzimas del citocromo P-450 y por lo tanto la probabilidad de interaccionar con otros fármacos concomitantes en la terapia del paciente es
Recibido: 27-08-2018

Aceptado: 18-12-2018

Disponible online: 28-12-2018 
Tabla 1 Estado de situación inicial

\begin{tabular}{|c|c|c|c|c|c|c|}
\hline \multicolumn{2}{|c|}{ Problemas de salud } & \multicolumn{5}{|c|}{ Medicamentos } \\
\hline Inicio & Problema de salud & Inicio & Medicamento & Pauta & $\begin{array}{c}\text { Via metabólica } \\
\text { (1) }\end{array}$ & $\begin{array}{c}\text { Proteinas } \\
\text { transportadoras } \\
(1,2)\end{array}$ \\
\hline \multirow[t]{4}{*}{ Años } & \multirow[t]{4}{*}{ Hipertensión } & años & Amlodipino $5 \mathrm{mg}$ & $1 / 0 / 0$ & $3 \mathrm{~A} 4$ & \\
\hline & & años & $\begin{array}{l}\text { Hidroclorotiazida } \\
12 \mathrm{mg}\end{array}$ & $1 / 0 / 0$ & No Citocromo & \\
\hline & & 6 meses & Olmesartán 40mg & $1 / 0 / 0$ & OATP1 & Inhibidor OATP1B1 \\
\hline & & años & Bisoprolol $2.5 \mathrm{mg}$ & $1 / 0 / 0$ & 2D6 & \\
\hline Años & Hipercolesterolemia & 1 año & Rosuvastatina 20 & 0/0/1 & No citocromo & Inhibidor OATP1B1 \\
\hline 2 años & Hiperuricemia & 2 años & Alopurinol 100 & $1 / 0 / 0$ & Xantina oxidasa & \\
\hline 2 años & Insomnio & 2 años & Lorazepam $1 \mathrm{mg}$ & 0/0/1 & $3 \mathrm{~A} 4$ & \\
\hline 4 años & Prevención cv & 4 años & AAS $100 \mathrm{mg}$ & $1 / 0 / 0$ & No Citocromo & \\
\hline 4 años & Prevención gástrica & 4 años & Omeprazol $20 \mathrm{mg}$ & & $2 \mathrm{C} 19,3 \mathrm{~A} 4$ & Inhibidor 2C19 \\
\hline 3 meses & Rotura tendón de Aquiles & 3 meses & Fisioterapia & & & \\
\hline
\end{tabular}

menor. Asimismo, como el paciente no sufre insuficiencia renal no hay riesgo de acumulación de la estatina activa en sangre y sería el fármaco óptimo para este paciente.

Debido a que el resultado de la interacción es la acumulación de Rosuvastatina activa en sangre por encima de los valores esperados según la bibliografía, decidimos intervenir disminuyendo la dosis de Rosuvastatina y no sustituyendo el fármaco.

\section{Intervención}

Con todos los datos anteriores se realizó un informe al médico, a través de una carta en sobre abierto, vía farmacéutico-paciente-médico, donde se le informaba al médico de la posible interacción entre Olmesartán y Rosuvastatina, y la aparición del efecto adverso causado por Rosuvastatina, aconsejando una disminución en la dosis de Rosuvastatina a $5 \mathrm{mg}$.

También se le solicitó que le realizara otro análisis de colesterol total transcurridos 3 meses del cambio de dosis para comprobar que sus valores de colesterol total seguían siendo adecuados.

\section{Resultados}

El médico aceptó la intervención y disminuyó la dosis de estatina a los valores recomendados por la farmacia citando al paciente a los 3 meses para repetir sus valores analíticos de colesterol total. A los 60 días del cambio de medicación, el paciente acudió a la farmacia a informarnos de que la mejoría era notable y que incluso era capaz de subir y bajar escaleras sin ninguna molestia. Cuando se le realizaron los nuevos análisis los valores siguieron siendo óptimos.

$\mathrm{Al}$ calcular el Algoritmo de $\mathrm{Na}-$ ranjo (4) para estimar la probabilidad de definir un efecto adverso causado por un fármaco, el valor obtenido fue de 7 lo que se corresponde al grado de PROBABLE como causa de la reacción adversa a medicamentos causada por Rosuvastatina. Del mismo modo, siguiendo la "Escala de Probabilidades de Interacciones farmacológicas" (5) se obtuvo un valor de 8 puntos lo que corresponde al grado de PROBABLE como causa de la interacción entre Olmesartán y Rosuvastatina. Por ello se decidió notificar la interacción al Sistema Español de Farmacovigilancia de medicamentos de uso humano, a través de su página web (6).

\section{Conclusiones}

Debido al aumento de la esperanza de vida de nuestros pacientes y al elevado número de medicamentos necesarios prescritos por paciente, a menudo el farmacéutico comunitario se encuentra incapaz de evaluar la terapia del paciente de manera efectiva en su día a día. Siguiendo un protocolo de estudio como el descrito en el caso anterior, en el que se evalúan de manera rápida las dosis prescritas, las rutas metabólicas utilizadas y las proteínas de transporte encargadas de la eliminación del fármaco, el estudio de la medicación se realiza de manera ágil y útil; aplicable en el trabajo cotidiano de la farmacia.

La farmacia comunitaria se presenta como el entorno perfecto para instaurar este servicio profesional farmacéutico asistencial debido a su papel integrador dentro de la Atención Primaria.

\section{Referencias bibliográficas}

1. Drugbank. Disponible en: https://drugbank.ca

2. Karlgren M, Vildhede A, Norinder U, Wisniewski JR, Kimoto E, Lai Y, Haglund U, Artursson P. Classification of inhibitors of hepatic organic anion transporting polypeptides (OATPs): influence of protein expression on drugdrug interactions. J Med Chem. 2012 May 24;55(10):4740-63. doi:10.1021/ jm300212s

3. Consejo General de Colegios Oficiales de Farmacéuticos. Bot PLUS 2.0. Disponible en: https://botplusweb.portalfarma.com

4. Naranjo CA, Busto U, Sellers EM, et al. A method for estimating the probability of adverse drug reactions. Clin Pharmacol Ther. 1981;30:239-245. doi: 10.1038/clpt.1981.154

5. Carlos Juárez-Giménez J, Lalueza-Broto P, Girona-Brumos L. Interacciones farmacológicas: escala de probabilidad de Horn. Medicina Clínica 2008;130(3): 119-119. doi:10.1157/13115364

6. Notificación de Sospechas de Reacciones Adversas a Medicamentos. Disponible en: https://notificaram.es 